\title{
Green biosynthesis of silver nanoparticles using Curcuma longa tuber powder
}

This article was published in the following Dove Press journal:

International Journal of Nanomedicine

24 October 2012

Number of times this article has been viewed

\author{
Kamyar Shameli ${ }^{1,2}$ \\ Mansor Bin Ahmad' \\ Ali Zamanian ${ }^{2}$ \\ Parvanh Sangpour ${ }^{2}$ \\ Parvaneh Shabanzadeh ${ }^{3}$ \\ Yadollah Abdollahi ${ }^{4}$ \\ Mohsen Zargar ${ }^{5}$ \\ 'Department of Chemistry, \\ Universiti Putra Malaysia, Serdang, \\ Selangor, Malaysia; ${ }^{2}$ Materials and \\ Energy Research Center, Karaj, \\ Iran; ${ }^{3}$ Department of Mathematics, \\ ${ }^{4}$ Advanced Materials and \\ Nanotechnology Laboratory, \\ Universiti Putra Malaysia, Serdang, \\ Selangor, Malaysia; ${ }^{5}$ Department \\ of Biology, Islamic Azad University, \\ Qom, Iran
}

\begin{abstract}
Green synthesis of noble metal nanoparticles is a vastly developing area of research. Metallic nanoparticles have received great attention from chemists, physicists, biologists, and engineers who wish to use them for the development of a new-generation of nanodevices. In this study, silver nanoparticles were biosynthesized from aqueous silver nitrate through a simple and eco-friendly route using Curcuma longa tuber-powder extracts, which acted as a reductant and stabilizer simultaneously. Characterizations of nanoparticles were done using different methods, which included ultraviolet-visible spectroscopy, powder X-ray diffraction, transmission electron microscopy, scanning electron microscopy, energy-dispersive X-ray fluorescence spectrometry, and Fourier-transform infrared spectroscopy. The ultraviolet-visible spectrum of the aqueous medium containing silver nanoparticles showed an absorption peak at around $415 \mathrm{~nm}$. Transmission electron microscopy showed that mean diameter and standard deviation for the formation of silver nanoparticles was $6.30 \pm 2.64 \mathrm{~nm}$. Powder X-ray diffraction showed that the particles are crystalline in nature, with a face-centered cubic structure. The most needed outcome of this work will be the development of value-added products from C. longa for biomedical and nanotechnology-based industries.
\end{abstract}

Keywords: silver nanoparticles, Curcuma longa, biosynthesis, green synthesis, transmission electron microscopy

\section{Introduction}

Green nanotechnology is an area with significant focus at present on the important objective of facilitating the manufacture of nanotechnology-based products that are eco-friendly and safer for all beings, with sustainable commercial viability. The "green synthesis" of metal nanoparticles receives great attention due to their unusual optical, chemical, photochemical, and electronic properties. ${ }^{1}$ Metal nanoparticles, especially the noble metals, have mainly been studied because of their strong optical absorption in the visible region caused by the collective excitation of free-electron gas. ${ }^{2}$

Among noble metal nanoparticles, silver nanoparticles (Ag-NPs) have a wide area of interest, as they have a large number of applications, such as in nonlinear optics, spectrally selective coating for solar energy absorption, biolabeling, intercalation materials for electrical batteries as optical receptors, catalyst in chemical reactions, and as antibacterial capacities.

Ag-NPs have particular properties that may perhaps have numerous applications in the fields of dentistry, clothing, catalysis, mirrors, optics, photography, electronics, and the food industry. ${ }^{3}$ Because of such a broad variety of applications, many different preparation methods have been developed. However, the methods developed for Ag-NP
Correspondence: Kamyar Shamel Department of Chemistry, Faculty of Science, Universiti Putra Malaysia, Serdang UPM 43400, Selangor, Malaysia Tel +60 I73443492

Fax +60389466043

Email kamyarshameli@gmail.com 
preparation must give preference to controlled size of AgNPs. Therefore, nanosilver with small particle size and devoid of aggregation between particles is favorable.

There are several ways to reduce $\mathrm{Ag}^{+}$, eg, use of $\gamma$-rays, ${ }^{4}$ ultraviolet (UV) irradiation, ${ }^{5}$ heating and electrochemical reduction, ${ }^{6}$ and application of reducing chemicals, such as hydrazine, ${ }^{7}$ sodium borohydride,${ }^{8-10}$ polyethylene glycerol, ${ }^{11}$ $N, N$-dimethylformamide, ${ }^{12}$ glucose, ${ }^{13}$ ethylene glycol, ${ }^{14}$ formaldehyde, ${ }^{15}$ and sodium in liquid ammonia. ${ }^{16}$ However, there is still need for a more economic, commercially viable, and environmentally green synthesis route to synthesize Ag-NPs. The green synthesis of Ag-NPs involves three main steps, which must be evaluated based on green chemistry perspectives, including selection of solvent medium, reducing agent, and nontoxic stabilizers for Ag-NPs. ${ }^{17}$

The biosynthesis of nanoparticles, which represents a connection between biotechnology and nanotechnology, has received increasing consideration due to the growing need to develop environmentally friendly technologies for material syntheses. The search for appropriate biomaterials for the biosynthesis of nanoparticles continues through many different synthetic methods. ${ }^{18}$

The biosynthetic method using plant extracts has received more attention than chemical and physical methods and even the use of microbes. The method is suitable for nanoscale metal synthesis due to the absence of any requirement to maintain an aseptic environment. ${ }^{19}$ The possibility of using plant materials for the synthesis of nanoscale metals was reported initially by Gardea-Torresdey et al. ${ }^{20,21}$ Later, the bioreduction of various metals to nanosize materials of various shapes, capable of meeting the requirements of diverse industrial applications, was extensively studied. ${ }^{22}$ In continuation, we have demonstrated the prospect of using Vitex negundo L leaf and Callicarpa manigayi stem-bark methanolic extracts for the synthesis of Ag-NPs in ambient conditions, without any additive protecting nanoparticles from aggregating, template shaping nanoparticles or accelerants..$^{23,24}$
In this study, the synthesis and characterization of Ag/Curcuma longa by a green method is reported. The Ag-NPs were prepared using silver nitrate as silver precursor and $C$. longa tuber-powder water extract as reducing agent and stabilizer.

\section{Materials and methods \\ Materials}

The C. longa tubers were purchased from a local market in Malaysia. $\mathrm{AgNO}_{3}$ (99.98\%) was used as a silver precursor, and was provided by Merck (Darmstadt, Germany). $\mathrm{HNO}_{3}$ (70\%) and $\mathrm{HCl}(37 \%)$ were obtained from Sigma-Aldrich (St Louis, MO). All reagents in this effort were analytical grade and were used as received without further purification. All solutions were freshly prepared using double-distilled water and kept in the dark to avoid any photochemical reactions. All glassware used in experimental procedures was cleaned in a fresh solution of $\mathrm{HNO}_{3} / \mathrm{HCl}(3: 1, \mathrm{v} / \mathrm{v})$, washed thoroughly with double-distilled water, and dried before use.

\section{Extraction preparation}

The $C$. longa plant and tubers are shown in Figure 1A and B. The $C$. longa tubers were washed to remove the adhering mud particles and possible impurities. Later they were dried under sunlight for a week to completely remove the moisture. The tubers were cut into small pieces, powdered in a mixer, and then sieved using a 20-mesh sieve to get uniform size range. The final sieved powder was used for all further studies (Figure 1C). For the production of extract, $0.1 \mathrm{~g}$ of $C$. longa tuber powder was added to a $100 \mathrm{~mL}$ Erlenmeyer flask with $20 \mathrm{~mL}$ sterile distilled water and then mixed for 4 hours at room temperature.

\section{Synthesis of $A g / C$. longa emulsion}

Briefly, water extract of $C$. longa tubers $(0.1 \mathrm{~g})$ was added to distilled deionized water $(20 \mathrm{~mL})$ with vigorous

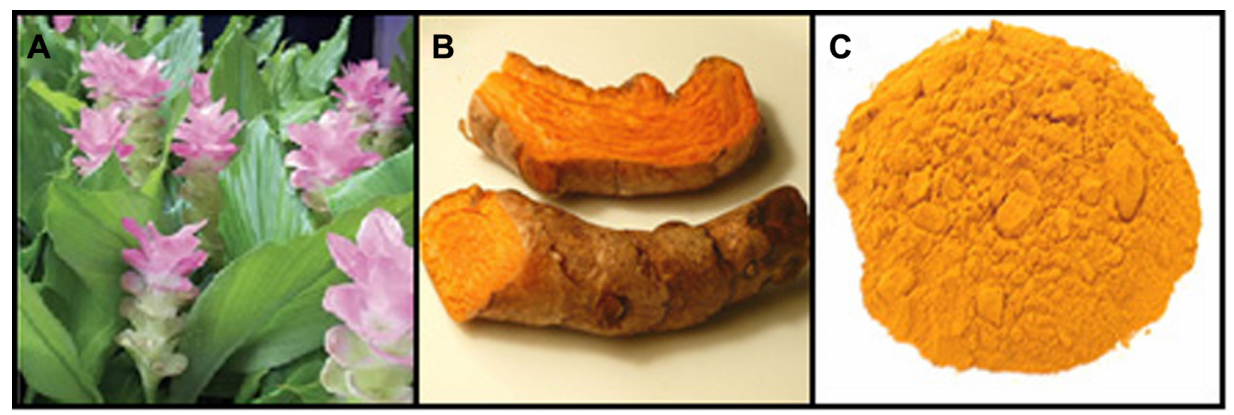

Figure I Curcuma longa plant (A), C. longa tubers (B), and C. longa powder (C). 
stirring for 4 hours. Forty milliliters of $\mathrm{AgNO}_{3}\left(1 \times 10^{-3}\right.$ $\mathrm{M})$ was then added and mixed at room temperature $\left(25^{\circ} \mathrm{C}\right)$ for 24 hours. Ag-NPs were gradually obtained during the incubation period. Throughout the reduction process, the solution was kept at a room temperature in the dark to avoid any photochemical reactions. The solution component was purged with nitrogen gas prior to use. Subsequently, reduction proceeded in the presence of nitrogen to eliminate oxygen. The obtained colloidal suspensions of Ag/C. longa were then centrifuged at 15,000 rpm for 20 minutes and washed four times to remove silver ion residue. The precipitate nanoparticles were then dried overnight at $30^{\circ} \mathrm{C}$ under vacuum to obtain the $\mathrm{Ag} / C$. longa.

\section{Characterization methods and instruments}

The prepared $\mathrm{Ag} / C$. longa were characterized by UV-visible spectroscopy, X-ray diffraction (XRD), transmission electron microscopy (TEM), scanning electron microscopy (SEM), energy dispersive X-ray fluorescence spectrometry (EDXRF) and Fourier-transform infrared (FT-IR) spectroscopy. The UV-visible spectra were recorded over the 300-800 nm range with a UV-1650 PC UV-visible spectrophotometer (Shimadzu, Osaka, Japan). The structures of the Ag-NPs produced were examined by XRD (XRD-6000; Shimadzu). The XRD patterns were recorded at a scan speed of $4 \%$ minute. TEM observations were carried out on a H-7100 electron microscope (Hitachi, Tokyo, Japan), and the particle-size distributions were determined using the UTHSCSA Image Tool version 3.00 program (freeware). SEM was performed using a Philips XL-30 instrument (Philips, Eindhoven, Netherlands) to study the morphology of $\mathrm{Ag} / C$. longa. The EDXRF was carried out on a DX-700HS spectrometer (Shimadzu). Meanwhile, the FT-IR spectra were recorded over the range of $400-4000 \mathrm{~cm}^{-1}$ using an FT-IR Series 100 , 1650 PerkinElmer spectrophotometer (Los Angeles, CA).

\section{Results and discussion}

The reduction of $\mathrm{Ag}^{+}$into $\mathrm{Ag}-\mathrm{NPs}$ during exposure to water extract of $C$. longa tuber powder was able to be followed by the color change. The fresh suspension of $C$. longa was yellow. However, after the addition of $\mathrm{AgNO}_{3}$ and stirring for 24 hours at room temperature, the emulsion turned brown.

The color changes in aqueous solutions are due to the surface-plasmon resonance (SPR) phenomenon (Figure 2A and $\mathrm{B})$. The result obtained in this investigation is interesting because it can serve as a foundation in terms of identification of potential forest plants for synthesizing Ag-NPs.

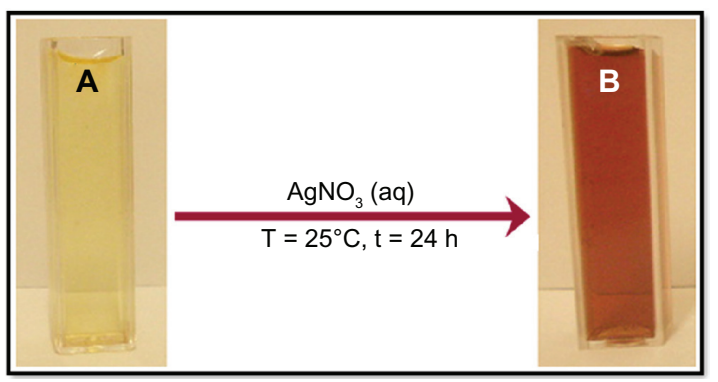

Figure 2 Photograph of Curcuma longa (A) and silver/C. longa (B) emulsions after 24 hours of stirring time.

C. longa as an aldehyde can reduce silver ions to Ag-NPs. The possible chemical equations for preparing the Ag-NPs are:

$$
\begin{aligned}
& \operatorname{Ag}_{(\mathrm{aq})}^{+}+\text {C. longa } \stackrel{\text { Stirring at room temp }}{\longrightarrow}[\mathrm{Ag}(C . \text { longa })]^{+}(1) \\
& {[\mathrm{Ag}(\text { C. longa })]^{+}+\mathrm{R}-\mathrm{CHO} \stackrel{\text { Stirring for } 24 \mathrm{~h}}{\text { at room temp }} \longrightarrow } {[\mathrm{Ag}(\text { C. longa })] } \\
&+\mathrm{R}-\mathrm{COOH}
\end{aligned}
$$

After dispersion of silver ions in the C. longa aqueous solution matrix (Equation 1), the extract was reacted with the $\mathrm{Ag}_{(\mathrm{aq})}^{+}$to form $[\mathrm{Ag}(\mathrm{C} \text {. longa })]^{+}$complex, which reacted with aldehyde groups in the molecular structure of the methanolic extract to form $[\operatorname{Ag}(C$. longa $)]$, due to the reduction of silver ions through the oxidation of aldehyde to carboxylic acid groups (Equation 2).

\section{UV-visible spectroscopy analysis}

The formation of Ag-NPs was followed by measuring the SPR of the C. longa and $\mathrm{Ag} / C$. longa emulsions over the wavelength range of 300-800 nm (Figure 3B). The SPR bands are influenced by the size, shape, morphology, composition, and dielectric environment of the prepared nanoparticles. ${ }^{25,26}$ Previous studies have shown that the spherical Ag-NPs contribute to the absorption bands at around 400-420 $\mathrm{nm}$ in the UV-visible spectra. ${ }^{26,27}$ These absorption bands were assumed to correspond to the Ag-NPs' extra-fine nature, with relatively small size. UV-visible absorption spectra (Figure 3B) showed that the broad SPR band contained one peak at $415 \mathrm{~nm}$. This peak illustrates the presence of a homogeneous distribution of hydrosol Ag-NPs after 24 hours stirring. ${ }^{11,23}$ For the stability test of the Ag-NP emulsion, the absorption spectrum of the sample was measured after storage for 3 months (Figure 3C). The absorption peak of the Ag-NPs shifted slightly from 415 to $417 \mathrm{~nm}$, but the spectra for these two samples showed significant changes in either peak intensity or spectral shape. ${ }^{27}$ Thus, with the comparison of Figure $3 \mathrm{~B}$ and $\mathrm{C}$, it can be 


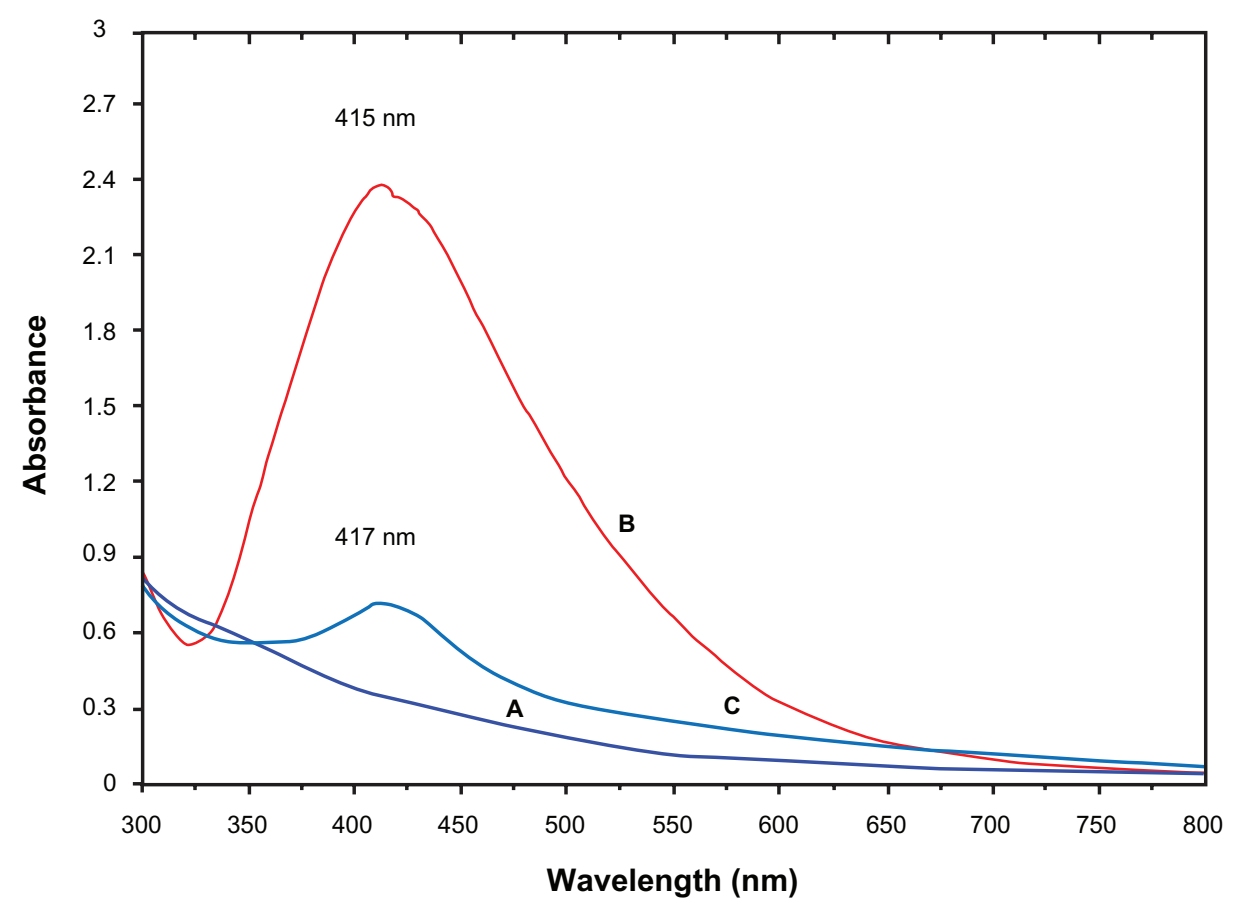

Figure 3 UV-visible absorption spectra of Curcuma longa (A) and silver (Ag)/C. longa emulsion (B) after 24 hours of stirring; Ag/C. longa emulsion (C) after 3 months.

concluded that for emulsion stability testing, due to the decreases in absorbance intensity and deposits of Ag-NPs, at first the stability of the $\mathrm{Ag} / \mathrm{C}$. longa emulsion decreases and then gradually the size of the Ag-NPs increases.

\section{Powder X-ray diffraction}

Figure 4 shows the XRD patterns of vacuum-dried Ag-NPs synthesized using C. longa. The XRD patterns of $\mathrm{Ag} / \mathrm{C}$. longa indicated that the structure of Ag-NPs is face-centered cubic. ${ }^{27}$ In addition, all the Ag-NPs had a similar diffraction profile, and XRD peaks at $2 \theta$ of $38.18^{\circ}$, $44.25^{\circ}, 64.72^{\circ}$, and $77.40^{\circ}$ could be attributed to the 111 , 200,220 , and 311 crystallographic planes of the face-centered cubic silver crystals, respectively. ${ }^{28}$ The XRD pattern thus clearly illustrated that the Ag-NPs formed in this study were crystalline in nature. The main crystalline phase was silver, and there were no obvious other phases as impurities were found in the XRD patterns (Figure 4).

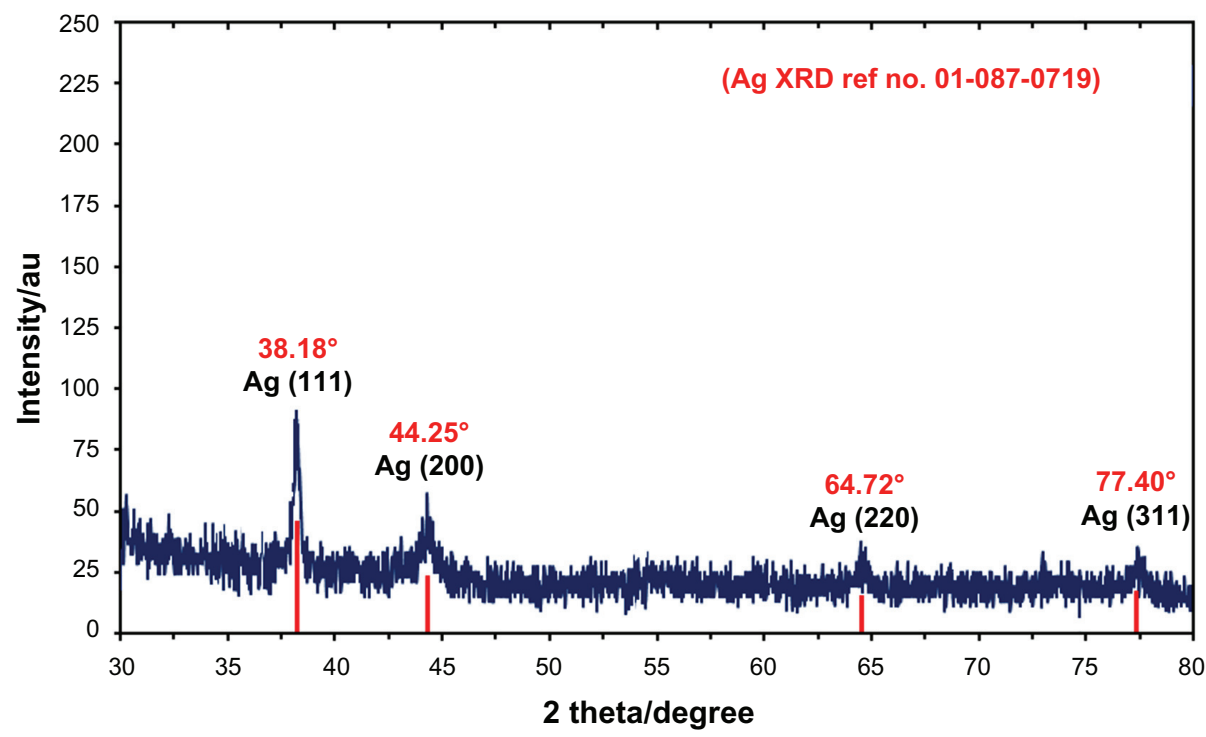

Figure 4 X-ray diffraction patterns of silver nanoparticles (Ag-NPs) synthesized in Curcuma longa for determination of Ag-NPs after 24 hours of stirring. Abbreviation: $\mathrm{XRD}$, X-ray diffration. 
The average particle size of Ag-NPs can be calculated using the Debye-Scherrer equation (3):

$$
n=\frac{K \lambda}{\beta \cos \theta}
$$

where $K$ is the Scherrer constant with value from 0.9 to 1 (shape factor), where $\lambda$ is the $\mathrm{X}$-ray wavelength (1.5418 $\AA$ ), $\beta_{1 / 2}$ is the width of the XRD peak at half-height and $\theta$ is the Bragg angle. From the Scherrer equation, the average crystallite size of Ag-NPs for the sample at 24 hours of stirring are found to be lower than $10 \mathrm{~nm}$ in size, which is also in line with the TEM results discussed later.

\section{Morphology study}

For TEM, a drop of the Ag-NP solution synthesized by treating silver nitrate solution with $C$. longa was deposited onto a TEM copper grid. After drying, the grid was imaged using TEM. The TEM images and their size distribution are shown in Figure 5A and B; the result showed narrow particle-size distributions, with diameters in the range of 3.66-8.94 nm. Moreover, the mean diameter and standard deviation of Ag-NPs was $6.30 \pm 2.64 \mathrm{~nm}$.

The presence of one narrow distribution of Ag-NPs in the TEM images is in accordance with the UV-visible spectral study. Figure 5C and D show the Ag-NPs surrounded by the extract of $C$. longa. The dark points in this figure represent the large-scale distribution of Ag-NPs. The Ag-NPs surrounded by C. longa extract is shown by TEM in Figure 5 and confirmed by FT-IR spectroscopy. The number of Ag-NPs counted for TEM imaging was around 483 at 24 hours stirring. Figure 6A-D shows the SEM images and EDXRF spectra for the $C$. longa and $\mathrm{Ag} / C$. longa emulsion after 24 hours stirring. These results confirm that extract of C. longa can effectively control the shape and size of the Ag-NPs.

The exterior surfaces of $\mathrm{Ag} / \mathrm{C}$. long $a$ due to the presence of small Ag-NPs become shiny in the spots' spherical shapes (Figure 6C). Figure 6B shows the EDXRF spectra for the $C$. longa; the peaks around 1.7, 2.8,3.8, and $4.5 \mathrm{keV}$ are related to the binding energies of C. longa. In Figure 6D, the peaks around $1.3,3.1,3.3$, and $3.4 \mathrm{keV}$ are related to the silver elements in the C. longa. ${ }^{29}$

Additionally, the EDXRF spectra for the $\mathrm{Ag} / C$. longa confirmed the presence of Ag-NPs in the tuber-powder extraction without any impurity peaks. From EDXRF spectra, it is clear that C. longa has a yield of $45.53 \%$ of Ag-NPs. The results indicate that the synthesized nanoparticles are composed of high-purity Ag-NPs.
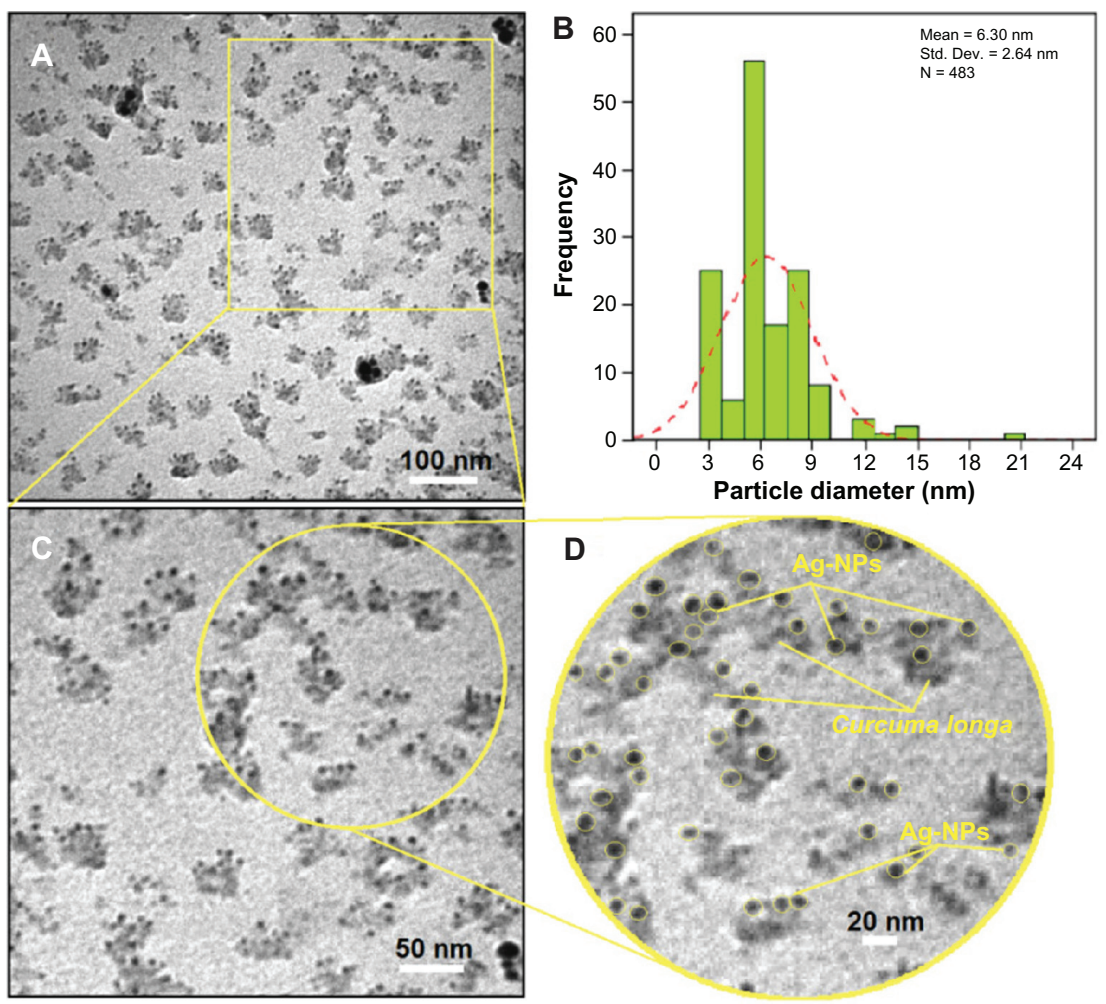

Figure 5 (A-D) Transmission electron microscopy images and corresponding size distribution of silver/Circuma longa after 24 hours of stirring. Abbreviations: Std Dev, standard deviation; Ag-NPs, silver nanoparticles. 

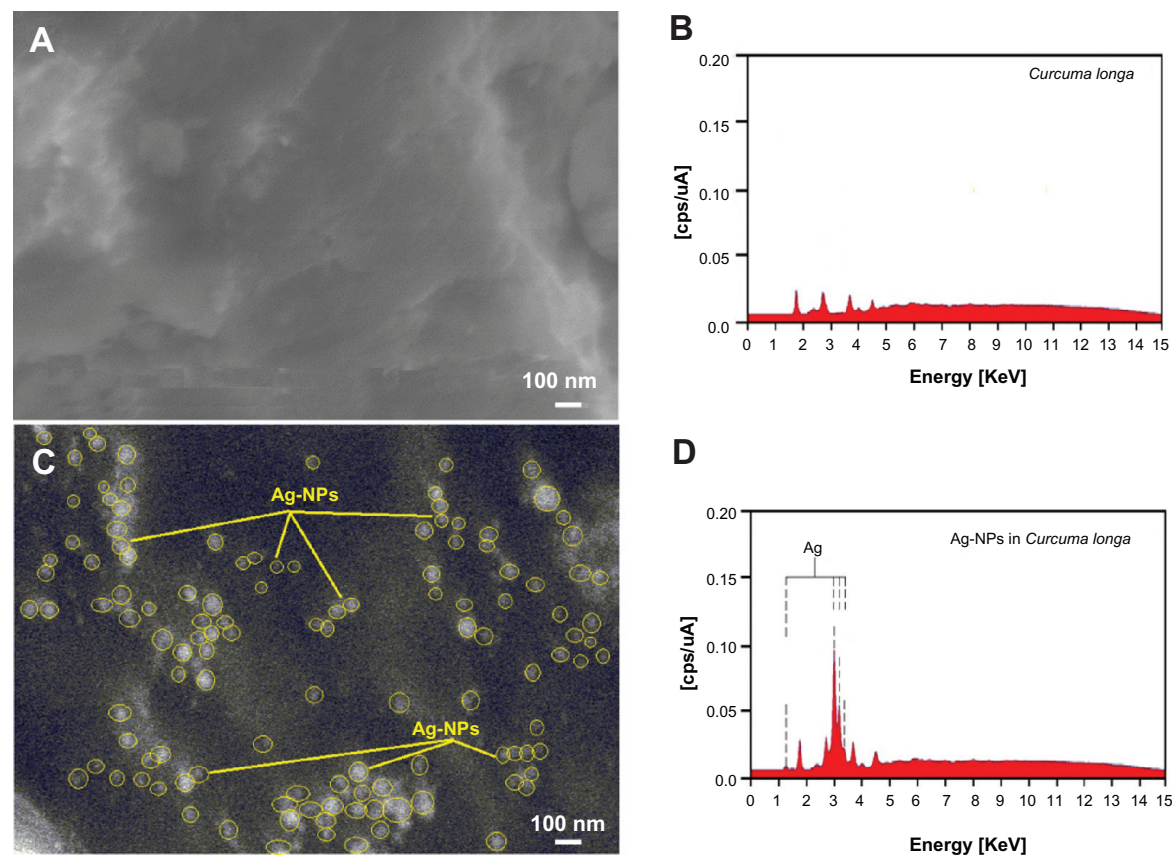

D

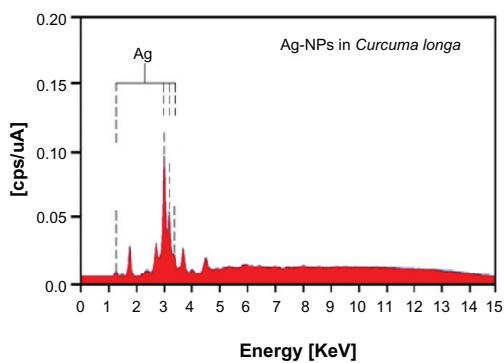

Figure 6 Scanning electron microscopy image and energy-dispersive X-ray fluorescence spectrometry spectra of Curcuma longa (A and B) and silver/C. longa (C and D) formation after 24 hours of stirring.

Abbreviation: Ag-NPs, silver nanoparticles.

\section{FT-IR chemical analysis}

The FT-IR spectra were recorded to identify the possible biomolecules responsible for the reduction of the $\mathrm{Ag}^{+}$ions and capping of the bioreduced Ag-NPs synthesized by the C. longa extract. After complete bioreduction of $\mathrm{Ag}^{+}$, the C. longa tuber-powder extract was centrifuged at $15,000 \mathrm{rpm}$ for 20 minutes to isolate the Ag-NPs from proteins and other compounds present in the solution. Figure 7A shows the FT-IR spectrum of $C$. longa tuber powder that did not contain $\mathrm{AgNO}_{3}$, whereas Figure 7B shows the spectrum containing
Ag-NPs after extract bioreduction with $\mathrm{AgNO}_{3}$. The spectrum in Figure 7A shows transmission peaks at 3295, 2923, $1638,1375,1134,1004,851,514$, and $393 \mathrm{~cm}^{-1}$. Similarly, transmission peaks for the tuber-powder extract containing Ag-NPs were at 3329, 2920, 1952, 1643, 1420, 1147, $1011,867,689,510$, and $299 \mathrm{~cm}^{-1}$. Three absorption peaks located around 867, 1011 and $1147 \mathrm{~cm}^{-1}$ can be assigned as the absorption peaks of $-\mathrm{C}-\mathrm{N}$ stretching vibrations of the amine, $-\mathrm{C}-\mathrm{O}-\mathrm{C}$ or $-\mathrm{C}-\mathrm{O}$ groups, respectively. ${ }^{24,30}$ The bonds or functional groups such as $-\mathrm{C}-\mathrm{O}-\mathrm{C}-,-\mathrm{C}-\mathrm{O}$, and

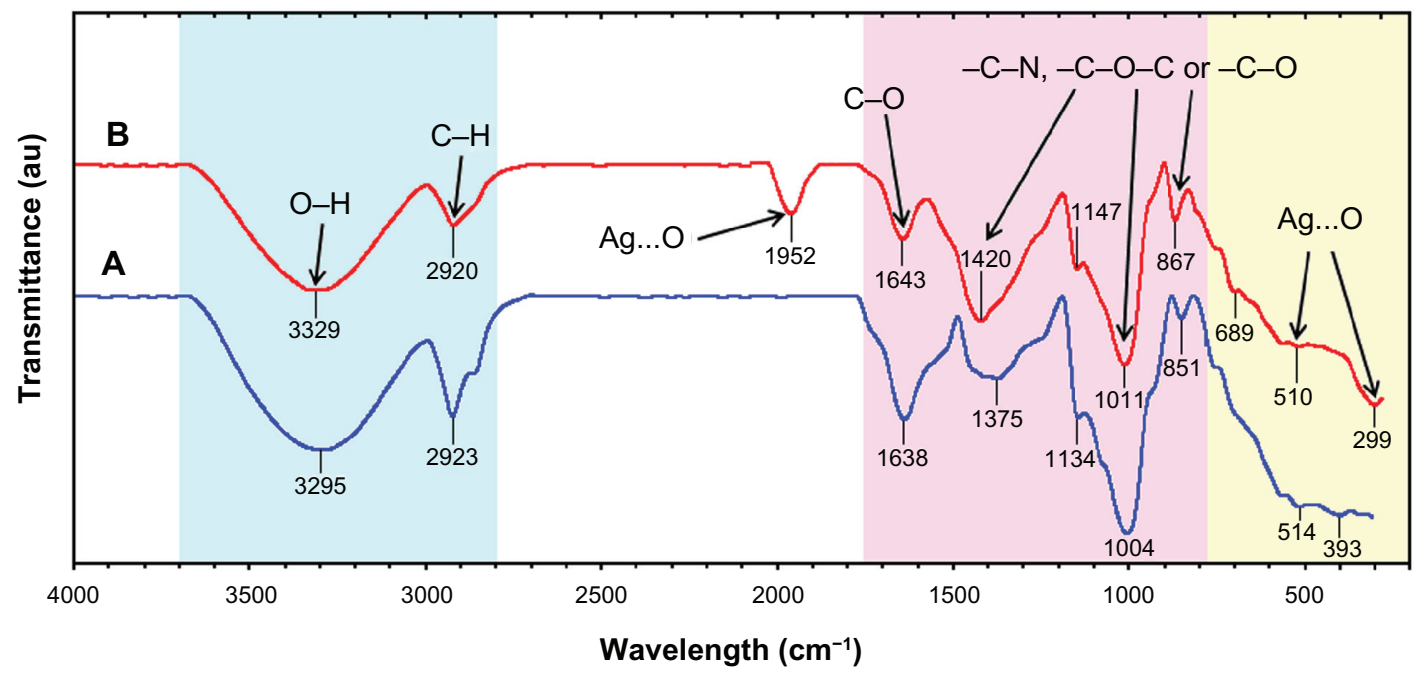

Figure 7 Fourier-transform infrared spectra for the Curcuma longa tuber-powder extract (A) and Ag/C. longa (B) after 24 hours from biosynthesis reaction. 
$-\mathrm{C}=\mathrm{C}-$ derived from heterocyclic compounds, eg, alkaloid or flavones, and the amide (I) bond derived from the proteins that are present in the tuber-powder extract are the capping ligands of the nanoparticles. ${ }^{31}$ The broad and strong bands at $3329-2920 \mathrm{~cm}^{-1}$ were due to bonded hydroxyl $(-\mathrm{OH})$ or amine groups $(-\mathrm{NH})$ and aliphatic $\mathrm{C}-\mathrm{H}$ of the C. longa tuber-powder extract, respectively. The peak at $1643 \mathrm{~cm}^{-1}$ is attributed to the carboxyl group $(-\mathrm{C}=\mathrm{O})$ stretching vibration. The adsorption at around $1375-1420 \mathrm{~cm}^{-1}$ notably showed that $-\mathrm{NO}_{3}$ existed in residual amounts. ${ }^{24}$ The broad peaks at 510 and $299 \mathrm{~cm}^{-1}$ and also the peak in $1952 \mathrm{~cm}^{-1}$ are related to Ag-NP banding with oxygen from hydroxyl groups of C. longa compounds (Figure 7B). ${ }^{27}$

\section{Conclusion}

Ag-NPs with an average size of $6.30 \pm 2.64 \mathrm{~nm}$ and spherical shapes were synthesized using aqueous tuber-powder extract of $C$. longa. The Ag-NPs were characterized by UV-visible, XRD, TEM, SEM, EDXRF, and FT-IR spectra. Biosynthesis of Ag-NPs using green resources like C. longa is a better alternative to chemical synthesis, since this green synthesis is pollutant-free and eco-friendly. From the results obtained in this research, one can affirm that $C$. longa tuber powder can play an important role in the bioreduction and stabilization of silver ions to Ag-NPs.

\section{Acknowledgments}

The authors thank the University Putra Malaysia (UPM) for its financial support (RUGS, Project no 9199840). The authors are also grateful to the staff of the Department of Chemistry, UPM, for their help in this research, and the Institute of Bioscience (IBS/UPM) for technical assistance.

\section{Disclosure}

The authors report no conflicts of interest in this work.

\section{References}

1. Mohanpuria P, Rana NK, Yadav SK. Biosynthesis of nanoparticles: technological concepts and future applications. J Nanopart Res. 2008;10: 507-517.

2. Mohamed MB, Volkov V, Link S, Sayed MAE. The 'lightning' gold nanorods: fluorescence enhancement of over a million compared to the gold metal. Chem Phys Lett. 2000;317:517-523.

3. Rai M, Yadav A, Gade A. Silver nanoparticles as a new generation of antimicrobials. Biotechnol Adv. 2009;27:76-83.

4. Shameli K, Ahmad MB, Wan Yunus WMZ, Ibrahim NA, Gharayebi Y, Sedaghat S. Synthesis of silver/montmorillonite nanocomposites using $\gamma$-irradiation. Int J Nanomedicine. 2010;5:1067-1077.

5. Shameli K, Ahmad MB, Wan Yunus WMZ, et al. Green synthesis of silver/montmorillonite/chitosan bionanocomposites using the UV-irradiation method and evaluation of antibacterial activity. Int $J$ Nanomedicine. 2010;5:875-887.
6. Zhang Y, Chen F, Zhuang J, et al. Synthesis of silver nanoparticles via electrochemical reduction on compact zeolite film modified electrodes. Chem Commun (Camb). 2002:2814-2815.

7. Szczepanowicz K, Stefańska J, Socha RP. Preparation of silver nanoparticles via chemical reduction and their antimicrobial activity. Physicochem Probl Miner Process. 2010;45:85-98.

8. Shameli K, Ahmad MB, Zargar M, Wan Yunus WMZ, Rustaiyan A, Ibrahim NA. Synthesis of silver nanoparticles in montmorillonite and their antibacterial behavior. Int J Nanomedicine. 2010;6: 581-590.

9. Shameli K, Ahmad MB, Wan Yunus WMZ, Ibrahim NA. Synthesis and characterization of silver/talc nanocomposites using the wet chemical reduction method. Int J Nanomedicine. 2010;5:743-751.

10. Shameli K, Ahmad MB, Zargar M, Wan Yunus WMZ, Ibrahim NA. Fabrication of silver nanoparticles doped in the zeolite framework and antibacterial activity. Int J Nanomedicine. 2011;6: 331-341.

11. Shameli K, Ahmad MB, Jazayeri SD, et al. Synthesis and characterization of polyethylene glycol mediated silver nanoparticles by the green method. Int J Mol Sci. 2012;13:6639-6650.

12. Pastoriza-Santos I, Liz-Marzán LM. Formation and stabilization of silver nanoparticles through reduction by N,N-dimethylformamide. Langmuir. 1999;15:948-951.

13. Ahmad MB, Shameli K, Wan Yunus WMZ, Ibrahim NA. Synthesis and characterization of silver/clay/starch bionanocomposites by green method. Aust J Basic Appl Sci. 2010;4:2158-2165.

14. Setua P, Pramanik R, Sarkar S. Synthesis of silver nanoparticle inside the nonaqueous ethylene glycol reverse micelle and a comparative study to show the effect of the nanoparticle on the reverse micellar aggregates through solvation dynamics and rotational relaxation measurements. J Phys Chem B. 2010;114:7557-7564.

15. Praus P, Turicová M, Klementová M. Preparation of silvermontmorillonite nanocomposites by reduction with formaldehyde and borohydride. J Braz Chem Soc. 2009;20:1351-1357.

16. Sun L, Zhang Z, Dang H. A novel method for preparation of silver nanoparticles. Mater Lett. 2003;57:3874-3879.

17. Raveendran P, Fu J, Wallen SL. Completely "green" synthesis and stabilization of metal nanoparticles. J Am Chem Soc. 2003;125: 13940-13941.

18. Sathishkumar M, Sneha K, Won SW, Cho CW, Kim S, Yun YS. Cinnamon zeylanicum bark extract and powder mediated green synthesis of nano-crystalline silver particles and its bactericidal activity. Colloid Surface B. 2009;73:332-338.

19. Rai A, Singh A, Ahmad A, Sastry M. Role of halide ions and temperature on the morphology of biologically synthesized gold nanotriangles. Langmuir. 2006;22:736-741.

20. Gardea-Torresdey JL, Parsons JG, Dokken K, et al. Formation and growth of $\mathrm{Au}$ nanoparticles inside live alfalfa plants. Nano Lett. 2002;2:397-401.

21. Gardea-Torresdey JL, Gomez E, Peralta-Videa JR, Parsons JG, Troiani H, Jose-Yacaman M. Alfalfa sprouts: a natural source for the synthesis of silver nanoparticles. Langmuir. 2003;19:1357-1361.

22. Shankar SS, Rai A, Ankamwar B, Singh A, Ahmad A, Sastry M. Biological synthesis of triangular gold nanoprisms. Nat Mater. 2004;3: $482-488$.

23. Zargar M, Hamid AA, Bakar FA, et al. Green synthesis and antibacterial effect of silver nanoparticles using Vitex negundo L. Molecules. 2011;16:6667-6676.

24. Shameli K, Ahmad MB, Al-Mulla EAJ, et al. Green biosynthesis of silver nanoparticles using Callicarpa maingayi stem bark extraction. Molecules. 2012;17:8506-8517.

25. Kelly KL, Coronado E, Zhao LL, Schatz GC. The optical properties of metal nanoparticles: the influence of size, shape and dielectric environment. J Phys Chem B. 2003;107:668-677.

26. Stepanov AL. Optical properties of metal nanoparticles synthesized in a polymer by ion implantation: a review. Tech Phys. 1997;49: 143-153. 
27. Shameli K, Ahmad MB, Jazayeri SD, et al. Investigation of antibacterial properties silver nanoparticles prepared via green method. Chem Cent J. 2012;6:73.

28. Ahmad MB, Shameli K, Darroudi M, Wan Yunus WMZ, Ibrahim NA. Synthesis and characterization of silver/clay nanocomposites by chemical reduction method. Am J Appl Sci. 2009;6:1909-1914.

29. Shameli K, Ahmad MB, Zargar M, et al. Synthesis and characterization of silver/montmorillonite/chitosan bionanocomposites by chemical reduction method and their antibacterial activity. Int J Nanomedicine. 2011;6:271-284.
30. Huang J, Li Q, Sun D, et al. Biosynthesis of silver and gold nanoparticles by novel sundried Cinnamomum camphora leaf. Nanotechnology. 2007; 18:1-11.

31. Luo L, Yu S, Qian S, Zhou T. Large-scale fabrication of flexible silver/ cross-linked poly(vinyl alcohol) coaxial nanoscale by a facial solution approach. J Am Chem Soc. 2005;127:2822-2823.

\section{Publish your work in this journal}

The International Journal of Nanomedicine is an international, peerreviewed journal focusing on the application of nanotechnology in diagnostics, therapeutics, and drug delivery systems throughout the biomedical field. This journal is indexed on PubMed Central, MedLine, CAS, SciSearch $\AA$, Current Contents ${ }^{\circledR} /$ Clinical Medicine,
Journal Citation Reports/Science Edition, EMBase, Scopus and the Elsevier Bibliographic databases. The manuscript management system is completely online and includes a very quick and fair peer-review system, which is all easy to use. Visit http://www.dovepress.com/ testimonials.php to read real quotes from published authors. 